\title{
Pós-VERDADE, NEOLIBERALISMO E CINISMO INSTITUCIONAL
}

\author{
Sergio Amadeu da Silveira
}

\begin{abstract}
Resumo
Este texto trata da conjuntura política brasileira e do processo que redundou no golpe de Estado que destituiu a presidente eleita Dilma Rousseff. Articulando as noções de regime de verdade, práticas discursivas e política de escândalo, o texto avança na descrição da formação de uma articulação das classes dominantes, corporações da mídia, Ministério Público e Poder Judiciário para destruir as possibilidades eleitorais das forças de esquerda no Brasil, abrindo caminho para a implementação do receituário neoliberal. Apropriando-se principalmente da ideia do combate à corrupção, os velhos esquemas do poder econômico organizam a construção de discursos e ações de Estado que compõem o cinismo institucional como política de Estado.
\end{abstract}

\section{Palavras-chave}

Cinismo institucional; pós-verdade; jogos de verdade; neoliberalismo; Brasil

\begin{abstract}
This text deals with the Brazilian political situation and the process that led to the coup d'état that brought down the elected president Dilma Rousseff. Expressing the notions of regime of truth, discursive practices and politics of scandal, the text moves forward with a description of the formation of a liaison between the dominant classes, media corporations, Public Prosecutor's Office and the Judiciary to destroy the electoral possibilities of the left-wing forces in Brazil, paving the way for the implementation of the neoliberal prescription. Making use for the most part of the idea of fighting corruption, the old economic power structures organize the construction of State speeches and actions that establish institutional cynicism as State policy.
\end{abstract}

\section{KEYWORDS}

Institutional cynicism; post truth; truth games; neoliberalism; Brazil

Em 1964, os generais brasileiros foram mobilizados para tomar o poder de Estado com a finalidade de barrar reformas importantes para a sociedade brasileira. $O$ presidente João Goulart foi deposto por um golpe de Estado que aplicou diretamente a força militar. Já na primeira década do século XXI, as forças do capital, dentre elas, o principal grupo de comunicação brasileiro, a Rede Globo, começaram a construir uma ação política com integrantes do Ministério Público e do Poder Judiciário para derrotar as forças de esquerda e desobstruir uma ampla gama de medidas visando implementar o receituário neoliberal no país. Para isso, era preciso remover do Poder Executivo as forças reformistas de centro-esquerda. A criminalização dos adversários e o uso do imaginário popular 
contra a corrupção foram os ingredientes fundamentais para tentar destruir a principal força de centro-esquerda no país. Em 2016, sem tanques nas ruas, o capital e as forças neofascistas utilizaram uma campanha sistemática nas diversas mídias, o Judiciário e o Ministério Público para consolidar seu golpe contra a democracia. Neste texto, identifico o novo modus operandi do neoliberalismo para a construção de um regime de verdade necessário à aplicação de suas medidas econômicas e políticas.

Para compreender o golpe judicial-midiático ocorrido no Brasil é preciso analisar o processo eleitoral. Empresas e empresários dominam a política brasileira, pois são os financiadores das eleições. No Código Eleitoral brasileiro, até 2014, além das pessoas físicas, somente pessoas jurídicas com fins lucrativos podiam financiar campanhas eleitorais. Pessoas jurídicas sem fins lucrativos estavam e estão proibidas de contribuir financeiramente nas eleições. As eleições brasileiras são organizadas claramente para o capital se reproduzir politicamente: "em contraste com os Estados Unidos, os sindicatos estão aparentemente ausentes do financiamento de campanha no Brasil. O motivo é que contribuições diretas de sindicatos são proibidas" (Samuels, 2007, p. 19). Os partidos políticos brasileiros, principalmente o PMDB (Partido do Movimento Democrático Brasileiro), o DEM (Democratas) e o PSDB (Partido da Social Democracia Brasileira), têm suas campanhas financiadas por dinheiro de empresários fornecedores e beneficiários diretos do Estado. Isso bem antes do início da Operação Lava Jato'. Por exemplo, o então presidente FHC - Fernando Henrique Cardoso e seus aliados do então PFL - Partido da Frente Liberal (atual DEM) tinham os custos de suas campanhas eleitorais pagos com dinheiro de bancos e consórcios que ganharam benefícios e licitações em sua gestão (Bradesco foi maior financiador de FHC, 1994). São exemplos: o grupo Telemar, a Andrade Gutierrez e os bancos Itaú e o Real/ABN-Amro (hoje inexistente), segundo as doações oficiais em 1998 (Freitas, Vaz \& Bramatti, 1998).

Quando o PT (Partido dos Trabalhadores) surgiu, nos anos de 1980, rejeitava o modo de financiamento de campanha tão comum entre os partidos da direita. A partir da chamada Nova República, os maiores financiadores de candidatos competitivos têm sido bancos, empresas privatizadas e corporações com grande relação com o Estado (Toledo, 2014; Agostine, Vieira \& Basile, 2006). Os custos das campanhas eleitorais no Brasil eram elevados até mesmo para os padrões norte-americanos (Samuels, 2007, p. 15). Depois de derrotas em sucessivas campanhas para o Poder Executivo Federal, com o crescimento constante do número de parlamentares e com a vitória em diversas prefeituras, cada vez mais o PT foi operando de modo semelhante aos partidos de direita. Para obter recursos com a finalidade de vencer as eleições dominadas pelo poder do dinheiro, o partido passou a financiar suas campanhas da mesma forma que o PSDB, DEM e PMDB. Aí está o ingrediente fundamental para compreender o golpe desfechado no Brasil.

Lula², beneficiado por uma conjuntura externa favorável e por uma acertada política de inclusão social, conseguiu indicadores positivos, seu partido cresceu e avançou

\footnotetext{
' A operação Lava Jato é uma investigação de corrupção e lavagem de dinheiro no Brasil.

2 Presidente da República do Brasil entre 2003 e 2010.
} 
eleitoralmente de modo consistente, tornando-se o maior partido de esquerda do Brasil. O PT e Lula nunca foram aceites pelos segmentos de renda elevada no país, muito menos eram considerados parceiros pelos dirigentes do grande capital, salvo diminutas exceções. Todavia, Lula e seus dirigentes davam a impressão de que acreditavam ter sido aceites pelas classes dominantes ou pelas elites econômicas. Mas, os sinais eram outros. Uma campanha distribuída e sistemática retomou as fórmulas vitoriosas de ataque à esquerda. A bandeira do combate à corrupção cinicamente passa a ser empunhada pelos principais partidos que utilizavam os mesmos métodos de financiamento de campanhas e de enriquecimento pessoal de seus quadros políticos (Michael \& Gramacho, 2000). O discurso corriqueiro no Brasil de que "todo político é ladrão" foi alterado para "nunca se viu tanta corrupção como hoje" ou "o PT sistematizou a corrupção no país". O cenário estava sendo montado desde a primeira reeleição de Lula. Era preciso criminalizar seletivamente a arrecadação de campanha e recontar a história do Brasil. Para realizar a primeira tarefa foi fundamental a articulação de lideranças do PSDB e do DEM com o Ministério Público e com o Poder Judiciário. Para a segunda missão, a Rede Globo foi o carro-chefe junto com articulações distribuídas, nem sempre combinadas, de diversos grupos empresariais e coletivos conservadores nas redes sociais.

\section{VERDADE, DISCURSO E PODER}

Para analisar o fenômeno conjuntural brasileiro em questão será preciso apresentar um arsenal conceitual. Começo pelo papel da construção da verdade e sua relação com o poder de Estado. Foucault nos trouxe a reflexão sobre a relação entre a verdade e o poder. Não é possível estruturar o sistema estatal e sua Justiça sem a construção de um conjunto de regras para distinguirmos o que é falso e o que é verdadeiro. Não importa se o que está sendo produzido como verdade se constitui naquilo que consideramos a verdade efetiva, verdadeira. A verdade tem um papel econômico, ela é organizadora dos processos no mercado e nos aparelhos do Estado. Foucault propôs problematizar a política não apenas em termos da ideologia e da sua relação com a ciência, mas do ponto de vista da verdade em sua interação com o poder.

Em nossas sociedades, a "economia política" da verdade tem cinco características historicamente importantes: a "verdade" é centrada na forma do discurso científico e nas instituições que o produzem; está submetida a uma constante incitação econômica e política (necessidade de verdade tanto para a produção econômica, quanto para o poder político); é objeto, de várias formas, de uma imensa difusão e de um imenso consumo (circula nos aparelhos de educação ou de informação, cuja extensão no corpo social é relativamente grande, não obstante algumas limitações rigorosas); é produzida e transmitida sob o controle, não exclusivo, mas dominante, de alguns aparelhos políticos ou econômicos (universidade, exército, escritura, meios de comunicação); enfim, é objeto de debate político e de confronto social (as lutas "ideológicas"). (Foucault, 1979, p. 13) 
O combate pela verdade é definidor do poder. Em sua aula inaugural no Collége de France, em 2 de dezembro de 1970, publicada como A Ordem do Discurso, Foucault advogou que o próprio sistema penal buscou sua justificação inicialmente na teoria do Direito, mas no século XIX tratou de buscá-la nos saberes sociológicos, médicos e psiquiátricos, ou seja, "como se a palavra da lei não pudesse mais ser autorizada em nossa sociedade, senão por um discurso de verdade" (Foucault, 2014, p. 18).

Os jogos de verdade são definidores de modos de existência e dos fluxos de poder que foram alicerçados pelos saberes científicos, particularmente, pelas ciências sociais. Organizam regimes discursivos que legitimam os discursos que devem ou não ser aceites. Aqui nos interessa a construção da verdade nas instituições, em especial no Poder Judiciário. Apresentado como neutro para a sociedade, os tribunais reivindicam que suas decisões se dão com base nas ciências jurídicas. Dos três poderes do Estado, o Judiciário é o que mais se coloca como guardião da verdade, como executor de procedimentos geradores de verdade.

No Brasil, o papel da instituição judicial nos jogos de verdade e no estabelecimento de regimes discursivos que permitem, por exemplo, tornar condutas políticas aceitáveis e não-aceitáveis não era evidente. A própria cultura política dos segmentos sociais, dos grupos profissionais e dos corpos parlamentares tinham em sua constituição a incorporação do modo como o Poder Judiciário e suas instituições fundamentais e de apoio construíam os modelos de respeito à lei, do aceitável e do inaceitável. O sistema político tinha assumido claramente como aceitável a participação direta dos empresários e seus negócios no processo de financiamento das eleições e de definição do gasto público. As forças de esquerda há muito denunciavam a ligação entre as classes dominantes e suas empresas com o poder. Curiosamente, doações de campanha de banqueiros que se beneficiavam das políticas econômicas dos partidos de direita nunca foram consideradas propinas. As privatizações de empresas para empresários e políticos ligados diretamente ao partido dos tucanos (PSDB) também eram aceites como legais, normais e legítimas. As denúncias contidas no livro Brasil Privatizado, do jornalista Aloysio Biondi, com milhares de cópias vendidas na década de 1990, não geraram nenhuma iniciativa do Ministério Público Federal. O relato minucioso de Biondi dos esquemas corrompidos da privatização fazem a Operação Lava Jato parecer pequena. Mesmo assim, o PT acreditou que os procedimentos judiciais seriam universais. Se a Odebrecht ${ }^{3}$ financiava políticos como Serra, Aécio, Alckmin e uma centena de outros, isso seria completamente aceitável para todo o espectro político.

O que a esquerda e a centro-esquerda brasileira perceberam parcialmente é que o financiamento de campanha de grande monta dava a elas competitividade eleitoral em um sistema plutocrático e formado para excluir os radicais. Esse aparente sucesso dessas forças de esquerda em aceitar o jogo da direita e vencê-lo era o caminho da sua derrota. As forças da direita conservadora perceberam que era preciso inviabilizar a possibilidade de vitória eleitoral do conglomerado de centro-esquerda. Isso conduziu a uma grande articulação que envolveu não somente parlamentares e militantes. As facções

\footnotetext{
${ }^{3}$ O Grupo Odebrecht foi criado em 1944, na Bahia, Brasil, e hoje está presente em 24 países.
} 
ligadas ao PSDB, aos demais partidos conservadores, como o DEM, foram acionadas para criar um processo de veridicção, um regime de verdade que permitisse a derrota do reformismo de centro-esquerda na política geral. O Judiciário que já era seletivo com os pobres, negros, índios, agora aplicaria sua experiente seletividade ao serviço da retomada do governo pela direita e pela aplicação das medidas neoliberais.

No ano de 2012, enquanto ocorriam as eleições municipais, durante o primeiro mandato de Dilma Roussef, sucessora de Lula, o Supremo Tribunal Federal, a corte constitucional brasileira, passou a transmitir diariamente o julgamento do que foi chamado de "mensalão", o escândalo baseado na acusação da compra de adesão parlamentar por parte de lideranças do governo e do PT para projetos do governo Lula. Com novas tecnologias de comprovação da verdade, se organizou argumentos e procedimentos que visavam construir narrativas de um grande assalto do poder praticado pelas forças de esquerda. Os melhores momentos do julgamento do "mensalão" eram selecionados pelos editores da Globo para serem reproduzidos nos telejornais e por jornais e revistas que operavam e operam os interesses de corporações nacionais e estrangeiras.

A verdade estava nas telas de TV, a política assumiu o banco dos réus. O senso comum de amplas camadas das classes médias confirmava seu novo bordão de que a corrupção tinha dominado o governo, combatida pela seriedade e protuberância dos magistrados, neutros e impolutos. Em 2012, já estava evidente a articulação entre membros influentes e dirigentes do Ministério Público Federal, juízes, donos da mídia, em especial, a família Marinho 4 e o comando tucano. O objetivo era claro: fulminar e destruir todas as possibilidades de reeleição da então presidenta Dilma que ocorreria em 2014 . A agenda do Judiciário seguia a estratégia eleitoral.

\section{Poder E COMUNiCAÇÃo ou A CULTURA Política do ESCÂNDALO}

Nas sociedades contemporâneas, organizadas pelo capitalismo tardio e informacional, a mobilização do senso comum tem ocorrido principalmente pela espetacularização (Debord, 1997) e, por sua vertente política mais usual que foi denominada de "política de escândalo" (Castells, 2015).

O que quero dizer com isso é que, bem antes do advento da sociedade em rede, a política de escândalos já era uma característica essencial na determinação de relações de poder e mudança institucional. Realmente, (...) a política de escândalos é uma forma de luta por poder mais enraizada e mais típica do que a condução da competição política ordenada segundo regras do Estado. (Castells, 2015, p. 297)

O fenômeno da política compreendida pelos cidadãos comuns como terreno de sucessivos escândalos é planetário e pode ter relação com o enfraquecimento da identificação partidária e com a autopromoção de figuras públicas acima dos interesses coletivos (Castells, 2015, p. 303). Contudo, esse fenômeno adquire uma força maior no Brasil,

${ }_{4}^{4}$ Detentora do Grupo Globo, Brasil, com várias empresas da área da informação e do entretenimento. 
com escassos períodos de democracia e com a sua herança do coronelismo político que articulava o nepotismo das elites políticas com o patrimonialismo na ocupação dos espaços públicos. Para boa parte da população, as pessoas se tornam políticos para enriquecer, ou seja, a corrupção seria o padrão da política brasileira.

Impor a corrupção como atributo da esquerda tem sido prática histórica e comum no Brasil e no mundo. Isso ocorre principalmente pela adesão da esquerda ao pragmatismo eleitoral. Durante o mensalão, tucanos e membros do DEM (todos eles acusados de corrupção) passaram a divulgar que a corrupção havia sido sistematizada nas gestões do PT. Ou seja, antes ela seria secundária, desorganizada, praticada por políticos isolados, não como um sistema de financiamento e manutenção no poder. Logo, pessoas de classe média passaram a repetir o bordão: "nunca a corrupção foi tão grande e tão sistêmica".

Após o bombardeio midiático de 2012 , com a popularização do mensalão, as forças conservadoras que articularam o espetáculo envolvendo o Judiciário e a mídia consideraram que a centro-esquerda seria derrotada nas eleições de 2014. Além de uma campanha sistemática na Rede Globo, a articulação conservadora, envolvendo Fundações e Think Tanks norte-americanos, financiaram grupos na Internet para amplificar o desgaste da esquerda e do governo Dilma. Desde 2012, uma série de organizações ligadas à direita e ao partido dos tucanos (PSDB) lançaram inúmeras páginas e perfis no Facebook com o tema do combate à corrupção. Quando o movimento autonomista do Passe Livre toma as ruas em junho de 2013 , os diversos coletivos conservadores e de direita estavam melhor posicionados para atrair a indignação e revolta dos jovens brasileiros.

Cabe ressaltar que os jovens de 20 anos, em 2013, tinham apenas 12 anos quando Lula iniciou a sua primeira gestão. Não vivenciaram a ditadura militar, o governo Sarneys e não tinham maturidade necessária para avaliarem a política e a economia do país nas gestões FHC. Assim, era muito fácil responsabilizar a gestão de centro-esquerda pelos problemas estruturais do Brasil. Desse modo, práticas discursivas apontariam as esquerdas como responsáveis pelas mazelas históricas da população e da juventude, principalmente nas periferias dos grandes centros urbanos. Entretanto, é preciso reconhecer que as gestões de Lula e Dilma pouco fizeram contra o legado de violência organizado nos tempos da ditadura, principalmente não atacaram a estrutura de militarização das polícias estaduais, nem atuaram efetivamente contra o extermínio da população negra nas periferias.

Apesar dos ataques ilimitados ao governo e ao principal partido de esquerda, Dilma Rousseff vence Aécio Neves em 2014. As forças conservadoras e o PSDB, inconformados, não aceitavam a derrota. Era necessário organizar um novo plano, mais contundente, mais articulado e destrutivo para o governo de centro-esquerda. Assim, as fortes ligações dos tucanos, banqueiros e ruralistas com os membros do Ministério Público e do Poder Judiciário tornaram-se estratégicas.

5 Governo de José Sarney (1985-1990), no período pós-ditadura militar no Brasil. 


\section{QUANDO MEMBROS DO JUDICIÁRIO SE ORGANIZAM COMO FORÇA POLÍ́TICA}

O juiz mais popular no país, Sergio Moro, ganhou notoriedade nos telejornais da Globo e na campanha sistemática para sua promoção. Juiz de Primeira Instância, tornou-se o ícone da Lava Jato pela superexposição midiática. Tornou-se líder político das forças da direita brasileira por realizar prisões de membros do PT e condenar o ex-presidente Lula a partir de ilações, delações e convicções. Sua carreira começa a se desgastar, uma vez que se tornaram evidentes os indícios de seletividade e perseguição de determinadas figuras públicas. Foi acusado de cometer crimes e de ter sido perdoado, sem punição, pelos membros da cúpula do Judiciário. Antes da Lava Jato, Moro criou uma carteira de identidade e CPF falsos para atender um pedido da polícia norte-americana, o que é ilegal no Brasil. Na Lava Jato assumiu que vazava informações para a imprensa, além de ter sido acusado de grampear a presidência da República.

O maior desgaste de Moro vem de suas fotos com diversos políticos tucanos e líderes da direita que agora estão sendo investigados por outras instâncias da Lava Jato. A imagem mais famosa é a em que aparece sorridente em uma animada conversa com o Senador Aécio Neves, no final de 2016. Questionado pelo jornal Folha de São Paulo, Moro afirmou: "Foi um evento público, e o senador não está sob investigação da Justiça Federal de Curitiba. Foi uma foto infeliz, mas não há nenhum caso envolvendo ele" (Moro diz que foto com Aécio foi 'infeliz', mas nega parcialidade, 2016). Ocorre que o Senador Aécio, no dia em que a foto foi tirada, já estava sob investigação do Ministério Público Federal. Seu nome já havia aparecido em diversos depoimentos ao próprio Moro. Posteriormente, foi gravado pela Polícia Federal, quando ficava evidente sua participação em esquemas de corrupção. O primo de Aécio Neves, citado em gravação, é filmado como portador de uma grande soma de dinheiro em espécie.

Moro escreveu um artigo na Revista Conselho de Justiça Federal, em 2004, sobre a Operação Mãos Limpas ou Mani Pulite que desmontou o sistema partidário italiano, atacando os esquemas de corrupção que o sustentavam. Os objetivos de Moro estavam bem delineados nesta importante passagem em que fala sobre o seu país:

no Brasil, encontram-se presentes várias das condições institucionais necessárias para a realização de ação judicial semelhante. Assim como na Itália, a classe política não goza de grande prestígio junto à população, sendo grande a frustração pelas promessas não-cumpridas após a restauração democrática. Por outro lado, a magistratura e o Ministério Público brasileiros gozam de significativa independência formal frente ao poder político. Os juízes e os procuradores da República ingressam na carreira mediante concurso público, são vitalícios e não podem ser removidos do cargo contra a sua vontade. $O$ destaque negativo é o acesso aos órgãos superiores, mais dependentes de fatores políticos. Destaque também negativo merece a concessão, por lei, de foro especial a determinadas autoridades públicas, como deputados e ministros, a pretexto de protegê-los durante o exercício do cargo. (Moro, 2004, p. 61) 
As agências do governo norte-americanas logo identificaram Moro como um importante aliado de seus objetivos no Brasil, publicamente definidos como o combate à lavagem de dinheiro e suas implicações criminosas. Os Estados Unidos têm periodicamente realizado cursos e seminários de formação de juízes e promotores brasileiros. Isso faz parte de uma estratégia de influência jurídica e política que visa preservar os interesses das corporações e do governo norte-americano. Tais atividades são relatadas por diversos autores. Um dos principais pensadores das relações internacionais e conselheiro em várias gestões da Casa Branca, Joseph Nye Jr. escreveu o livro O Paradoxo do poder americano. Nele, Nye Jr. baseando-se na teoria do poder brando afirma que é fundamental a utilização da persuasão e da cooptação em vez da coação. Afirma que os Estados Unidos devem definir a agenda política e a preferência dos povos.

O juiz Moro tratou de seguir na Lava Jato os passos ou as lições que estavam presentes em seu artigo de 2004. Tais ações foram fundamentais para consolidar na população um senso de verdade incontestável, uma crença de que a corrupção seria eliminada destruindo as forças de esquerda e seus líderes corruptos. Observe a passagem que reforça a política de escândalo, apontada por Castells (2015), nos jogos de verdade, ou melhor, na construção da verdade pela instituição que se apresenta como politicamente neutra:

os responsáveis pela operação mani pulite ainda fizeram largo uso da imprensa. Com efeito: Para o desgosto dos líderes do PSI, que, por certo, nunca pararam de manipular a imprensa, a investigação da "mani pulite" vazava como uma peneira. Tão logo alguém era preso, detalhes de sua confissão eram veiculados no "L'Expresso", no "La Republica" e outros jornais e revistas simpatizantes. Apesar de não existir nenhuma sugestão de que algum dos procuradores mais envolvidos com a investigação teria deliberadamente alimentado a imprensa com informações, os vazamentos serviram a um propósito útil. O constante fluxo de revelações manteve o interesse do público elevado e os líderes partidários na defensiva. Craxi, especialmente, não estava acostumado a ficar na posição humilhante de ter constantemente de responder a acusações e de ter a sua agenda política definida por outros. (Moro, 2005, p. 59)

Fica clara a importância da mobilização da opinião pública na estratégia de Moro. Também é evidente o papel da desmoralização dos suspeitos que deveriam ser condenados previamente pela mídia. O pensamento de Moro era completamente adequado aos interesses golpistas da direita conservadora, dirigida então pelo PSDB e pela Rede Globo.

\section{PóS-VERDADE, FAKE NEWS E CINISMO INSTITUCIONAL}

O Brasil vive uma conjuntura que pode ser denominada de "cinismo institucional" principal característica da economia comunicacional que organiza atualmente o regime 
de verdade político-judicial no país. A razão incongruente, incoerente e seletiva está presente nas práticas discursivas amplamente aceites por operadores do Ministério Público, do Poder Judiciário e das corporações da mídia. Notícias falsas ou fake news podem ser definidas como informações comprovadamente falsas, produzidas intencionalmente com o objetivo de influenciar a opinião pública (Allcott \& Gentzkow, 2017, pp. 213-214). O "cinismo institucional" não pode ser reduzido ao debate sobre o fake news ou a simples caracterização de opiniões embasadas em notícias falsas. Trata-se da organização de verdades que sabidamente não possuem comprovação empírica, que visam sustentar velhos privilégios das classes mais abastadas, que se desenvolvem com a nítida intenção de obter o apoio da opinião pública mesmo quando sustentadas na aplicação seletiva da lei, na completa incoerência de atitudes.

A característica central do cinismo institucional é organizar a estratégia comunicacional ou judicial com base exclusivamente em objetivos políticos, pouco se importando com os limites da lei ou com a coerência de sua aplicação. Desse modo, as urgências neoliberais e as forças da direita parecem impor um retorno ao período do coronelismo político. Victor Nunes Leal, ao analisar a organização policial e judiciária brasileira no período imperial, descreveu a Justiça dominada pelo espírito partidário, sendo um dos instrumentos principais do poder dos coronéis, líderes políticos locais e senhores da terra. Leal advoga que mesmo com a instalação da República, as estruturas judiciais e policiais agiam conforme o lema "fazer justiça aos amigos e aplicar a lei aos adversários" (Leal, 2012, p. 137). A atual partidarização do Judiciário brasileiro parece aplicar com maestria esse lema.

O trecho a seguir, do artigo do juiz Sergio Moro, expõe claramente que o objetivo da condenação do suspeito parece estar bem acima da verdade e da presunção de inocência tão cara ao Estado de Direito:

há sempre o risco de lesão indevida à honra do investigado ou acusado. Cabe aqui, porém, o cuidado na desvelação de fatos relativos à investigação, e não a proibição abstrata de divulgação, pois a publicidade tem objetivos legítimos e que não podem ser alcançados por outros meios. As prisões, confissões e a publicidade conferida às informações obtidas geraram um círculo virtuoso, consistindo na única explicação possível para a magnitude dos resultados obtidos pela operação mani pulite. (Moro, 2004, p. 59)

Moro assume claramente que a publicidade e a mobilização da opinião pública são elementos fundamentais da Justiça. Parece desconhecer que a Justiça não é um tribunal de exceção e que os riscos de casos como as precipitadas acusações contra os professores da Escola Base, em São Paulo, indicam que é fundamental preservar suspeitos até que o processo tenha encerrado definitivamente. Todavia, a passagem indica que seria fundamental para a Justiça destruir a reputação do acusado como parte da estratégia de investigação. Esta, por sua vez, nada tem a ver com a busca da confirmação ou negação das hipóteses, tal como faz um cientista. A investigação revindicada pela estratégia do cinismo institucional visa encontrar elementos que permitam dar uma impressão de verdade. 
O cinismo institucional trabalha com a seletividade, proteção dos aliados e com a ação política direta do Poder Judiciário junto à opinião pública, com o constante uso de exceções para atingir os objetivos políticos pré-definidos. A disseminação do cinismo institucional nas estruturas essenciais da Justiça se deu pelo crescimento do regime de verdades do neoliberalismo que pretende redesenhar o Direito em função da aplicação de seu receituário econômico. Tudo que estiver impedindo a lógica neoliberal deve ser removido, se possível criminalizado. Assim, as forças da direita neoliberal brasileira se unem com os velhos conservadores patrimonialistas que cinicamente se dizem contrários à corrupção, como demonstra a história de Aécio Neves, Michel Temer, Eduardo Cunha, entre tantos outros líderes do golpe que destrói o Brasil. A partidarização do Ministério Público e do Judiciário é essencial para o neoliberalismo. Com o desgaste da representação política, os operadores do neoliberalismo abriram espaço para os magistrados ocuparem a linha de frente da ação política direta. O combate à corrupção foi o mote para a remoção seletiva das forças políticas de centro-esquerda e para aplicação de medidas revindicadas pelas corporações globais e pelo capital financeiro.

\section{REFERÊNCIAS BIBLIOGRÁFICAS}

Agostine, C.; Vieira, A. \& Basile, J. (2006, 29 de novembro). Vale lidera lista de doadores à campanha de reeleição de Lula. G1. Valor OnLine. Retirado de http://g1.globo.com/Noticias/Politica/O,,AA1368133 5601,00-VALE+LIDERA+LISTA+DE+DOADORES+A+CAMPANHA+DE+REELEICAO+DE+LULA.html

Allcott, H. \& Gentzkow, M. (2016). Social Media and Fake News in the 2016 Election. Journal of Economic Perspectives, 31(2), 211-236.

Biondi, A. (2003). O Brasil privatizado. Um balanço do desmonte do Estado. São Paulo: Editora Perseu Abramo.

Castells, M. (2015). O poder da comunicação. São Paulo/Rio de Janeiro: Paz e Terra.

Moro diz que foto com Aécio foi 'infeliz', mas nega parcialidade (2016, 9 de dezembro). Folha de São Paulo. Retirado de http://www1.folha.uol.com.br/poder/2016/12/1840125-moro-diz-que-foto-com-aecio-foiinfeliz-mas-nega-parcialidade.shtml

Debord, G. (1997). A sociedade do espetáculo: comentários sobre a sociedade do espetáculo. Rio de Janeiro: Contraponto.

Foucault, M. (1979). Microfisica do poder. Rio de Janeiro: Edições Graal.

Foucault, M. (2014). A ordem do discurso: aula inaugural no Collège de France, pronunciada em 2 de dezembro de 1970. São Paulo: Edições Loyola.

Freitas, S. de; Vaz, L. \& Bramatti D. (1998, 26 de novembro). Bancos lideram doações para campanha de FHC. Folha de São Paulo. Retirado de http://www1.folha.uol.com.br/fsp/brasil/fc26119803.htm

Leal,V. N. (2012). Coronelismo, enxada e voto. O município e o regime representativo no Brasil. São Paulo: Companhia das Letras.

Michael, A. \& Gramacho, W. (2000, 19 de novembro). Comitê de FHC omitiu doações em 1994. Folha de São Paulo. Retirado de http://www1.folha.uol.com.br/folha/brasil/ultg6u11155.shtml

Moro, S. F. (2004). Considerações sobre a operação mani pulite. Revista CEJ, 8(26), 56-62. 
Nye Jr., J. (2002). O paradoxo do poder norte-americano. São Paulo: UNESP.

Samuels, D. (2007). Financiamento de campanhas no Brasil e propostas de reforma. Suffragium - Rev. do Trib. Reg. Eleit. do Ce, Fortaleza, 3(4), 1-172.

Bradesco foi maior financiador de FHC (1994, 2 de dezembro). Folha de São Paulo. Retirado de http://www1. folha.uol.com.br/fsp/1994/12/02/brasil/45.html

Toledo, J. R. (2014, 15 de setembro). Doações de campanha somam R\$ 1 bi, das quais metade vem de 19 empresas.O Estadão. Retirado de http://politica.estadao.com.br/noticias/ geral,doacoes-de-campanha-somam-r-1-bi-das-quais-metade-vem-de-19-empresas-imp-,1560289

\section{NotA BIOGRÁFICA}

Sérgio Amadeu da Silveira é licenciado em Ciências Sociais (1989), mestre (2000) e doutor em Ciência Política pela Universidade de São Paulo (2005). É professor adjunto da Universidade Federal do ABC (UFABC).

E-mail: sergio.amadeu@ufabc.edu.br

Endereço: Sala 367, Bloco Delta, Câmpus São Bernardo do Campo, Alameda da Universidade $s / n^{\circ}$ - Bairro Anchieta - São Bernardo do Campo - SP, CEP o9606-045, Brasil

\section{* Submetido: 29-09-2017}

* Aceite: 30-10-2017 